\title{
O Estado e os Planos de Saúde no Brasil
}

\author{
Carlos Octávio Ocké Reis
}

\section{Introdução}

No Brasil, a partir da década de 60, o Estado viabilizou a expansão dos planos de saúde por meio de mediações com os gastos públicos da assistência médica previdenciária. Entretanto, esse serviço cresceu a passos largos, "independentemente", nas décadas de 70 e 80 , todavia, impulsionado pelos incentivos governamentais. Essa trajetória permitiu que os planos rapidamente configurassem um mercado tipicamente capitalista.

Essa tipicidade caracterizou-se exatamente pela existência de ramos capitalistas autônomos descolados dos gastos públicos em saúde. Sua dinâmica de acumulação, entretanto, residiu parcialmente na eficiência econômica das empresas médicas: embora a dinâmica dos ramos capitalistas autônomos não estivesse mais vinculada àqueles gastos, já há algum tempo, estaria sendo patrocinada pela renúncia de arrecadação fiscal do Estado. Desse modo, o pólo dinâmico do mercado de serviços de saúde, o setor autônomo, acabou mantendo relações financeiras estruturais com o Estado.

Nos anos 90, as crises fiscal e financeira do Estado brasileiro combinadas ao alargamento da hegemonia neoliberal favoreceram a posição do setor privado no modelo assistencial: adicionada à força econômica, política e organizacional do setor privado tradicional, que ocupa uma posição privilegiada no conjunto da rede do Sistema Único de Saúde (SUS) - 75\% dos leitos; $83 \%$ das clínicas médico-ambulatoriais; e $40 \%$ das unidades de complementação diagnóstica e terapêutica (Viacava \& Bahia 1996) — nessa década há uma ascensão dos planos no sistema nacional de saúde.

Economista e pesquisador da Diretoria de Estudos Sociais do Instituto de Pesquisa Econômica Aplicada /IPEA Doutorando da Escola de Pós-graduação em Saúde Coletiva, Instituto de Medicina Social/ IMS/UERJ,

Rio de Janeiro 
Essa predominância do mercado na cobertura dos serviços sanitários seja no financiamento, seja na prestação, derivou evidentemente da falência da produção de serviços de saúde no bojo da esfera pública. Em outros termos, verificou-se o colapso da oferta e da qualidade dos serviços públicos de saúde e, em decorrência, a consolidação dos planos.

Esse mercado, portanto, apresenta-se como uma alternativa viável na configuração do novo modelo assistencial e conta com um cenário bastante fértil, embora com alto grau de incerteza do ponto de vista da equiidade para sua reprodução econômica:

- trata-se de um benefício que funciona como salário indireto, dirigido sobretudo à População Economicamente Ativa (PEA), em que pese que o mercado de trabalho esteja sofrendo profundas transformações (desemprego estrutural, terceirização, precarização etc.);

- o Estado brasileiro vem co-financiando os planos de saúde: a) viabilizando o seu consumo, mediante a dedução do Imposto de Renda de Pessoa Física e Jurídica ${ }^{1}$; b) concedendo outros incentivos, (p. ex., isenção da cota patronal sobre a folha de salários) decorrentes do status de filantropia conquistado pelas empresas médicas que desempenhavam atividades nitidamente lucrativas ${ }^{2}$; c) prestando os serviços de saúde de alto custo, como as doenças de longa duração e as cirurgias de maior complexidade para a clientela da medicina privada (o que acabou trazendo para agenda da regulamentação o tema do ressarcimento);

- os planos de saúde (sobretudo as modalidades de autogestão) são ofertados em diversas instituições da administração direta, indireta e do setor produtivo estatal. Por sua vez, o Governo Federal, ao alocar $\mathrm{R} \$ 24,00$ per capita aos servidores públicos com recursos financeiros do Orçamento da Seguridade Social (OSS), torna forçosamente seu gasto público em saúde iníquo. Nessa perspectiva, comprova-se o seguinte dilema: o próprio Estado evidencia a falência do SUS ao não propor alternativas médico-assistenciais para os trabalhadores do setor público, revelando o caráter complexo da sua relação com os planos;

- os serviços do SUS estão cada vez mais sendo contaminados pelos planos de saúde devido à estratégia de sobrevivência de algumas unidades públicas de saúde (sobretudo os hospitais universitários e as fundações) e do setor privado tradicional (Mendes 1994). Vale dizer que esse contágio pode ser dispersado pelo processo de reforma administrativa em curso - tendo por base a introdução das organizações sociais e de outras formas de gestão autônoma;

- o crescimento da oferta dos planos acompanha as propostas difundidas pelas agências internacionais. O Banco Mundial aposta no fortalecimento do mercado, no que tange ao financiamento e prestação dos serviços de saúde: 
“(...) será necessário que os governos promovam maior diversidade e concorrência no financiamento e prestação de serviços de saúde (...). O governo deixaria a cobertura de serviços clínicos remanescentes para o financiamento privado, via de regra com mediação de seguros (...)" (Banco Mundial 1993: iv);

- detendo um mercado do tamanho da população da Espanha (40 milhões de usuários), os planos expandem-se, abrindo novas fronteiras de acumulação no âmbito da proteção social.

Nessa direção, o modelo médico-assistencial brasileiro vem se orientando não nos marcos do previdencialismo alemão, tampouco do universalismo cubano, mas perversamente similar ao modelo americano, no qual, a grande maioria das pessoas paga por formas privadas de atenção médica (Medici 1991; Vianna 1995). Assim, o modelo alinha-se à nova idéia-força na era da globalização: a saúde como um bem privado.

Esse alinhamento sedimenta-se com a intensificação do fenômeno da universalização excludente ${ }^{3}$ :se inicialmente esse movimento excluiu da clientela do SUS os assalariados do mercado formal de trabalho, supõese que agora ele comece a expulsar os setores médios do mercado informal (conta própria e sem carteira assinada).

Isso repõe e multiplica os desafios da relação entre o Estado e os planos de saúde, sobretudo no que tange à sua regulamentação.

\section{Setor privado autônomo, ma non troppo}

O Estado brasileiro é o principal provedor das ações e serviços do setor saúde com o maior volume de cobertura. Agrega-se a isso que estimativas realizadas para o ano de 97 apontam que do total dos gastos público e privado em saúde, 55,2\% foram efetuados entre os níveis federal $(59,4 \%)$, estadual $(23,7)$ e municipal $(16,9 \%)^{4}$. Em que pese essa constatação, não se deve induzir que uma análise dos planos de saúde pode ocultar suas relações financeiras com o Estado:

"Diversas podem ser as formas de atuação do Estado no campo da saúde (...): concessão de subsídios, isenções fiscais ou incentivos (...) à população ou para certos segmentos desta" (Medici 1990b:7).

Posto isso, cabe inicialmente apontar que o mercado financiador e prestador de serviços privados de saúde (pré-pagamento e autogestão) é composto pelas: seguradoras de saúde, nas quais consultas, exames e hospitalizações são cobertas e reembolsadas pela entidade seguradora, respeitando os tetos (ou franquias) dos contratos de seguros; empresas de medicina de grupo, que administram principalmente planos de saúde para empresas e, em menor porte, para famílias. Existem várias modalidades 
de planos, desde os mais simples até as alternativas de livre escolha, em geral destinadas às famílias de alto poder aquisitivo ou às burocracias especializadas privada e pública. Em geral, esses planos são custeados por um sistema de pré-pagamento; cooperativas médicas, custeadas da mesma forma, nos quais médicos são simultaneamente sócios da cooperativa e prestadores de serviços. A UNIMED representa a quase totalidade do mercado de cooperativas médicas; e, finalmente, pelos planos de autogestão, onde as empresas ou administram seus próprios programas de saúde, ou contratam empresas para administrá-las, tendo por base os sistemas de pós-pagamento (op. cit.) $)^{5}$.

Uma estimativa quantitativa da cobertura por tipos de empresas que ofertam planos apresenta os seguintes dados:

Tabela 1: Estimativa de beneficiários por modalidades da assistência médica suplementar. Brasil, 1995

\begin{tabular}{l|c}
\hline Planos & $\begin{array}{l}\text { Estimativa de Beneficiários } \\
\text { (em milhões) }\end{array}$ \\
\hline Medicina de Grupo & 15 a 16 \\
\hline Cooperativas Médicas & 8 a 8,5 \\
\hline Planos de Autogestão & 8 \\
\hline Seguro Saúde & 3 a 4 \\
\hline Total & 34 a 36,5 \\
\hline
\end{tabular}

Fonte: Fórum Nacional de Seguro Saúde - 1996 e Arthur Andersen — Análise Setorial do Mercado Segurador — 1995/1996 — apud Bahia (1997).

Do ponto de vista do faturamento dos planos, observa-se os valores abaixo relacionados:

Tabela 2: Preço e faturamento dos planos, segundo modalidades da assistência médica suplementar. Brasil, 1995

\begin{tabular}{l|c|c}
\hline \multirow{2}{*}{ Planos } & $\begin{array}{l}\text { Preço médio corrente } \\
\text { Plano individual /ano }\end{array}$ & $\begin{array}{l}\text { Faturamento/ano } \\
\text { Valores correntes }\end{array}$ \\
\cline { 2 - 3 } & $\mathrm{R} \$$ & (em bilhões de R $\$$ ) \\
\hline Medicina de Grupo & 240,00 & 3,60 \\
\hline Cooperativas Médicas & 240,00 & 1,92 \\
\hline Planos de Autogestão & 456,00 & 3,36 \\
\hline Seguro Saúde & 360,00 & 1,44 \\
\hline Total & --- & 10,32 \\
\hline
\end{tabular}

Fonte: Fórum Nacional de Seguro Saúde — 1996 (apud op. cit.). 
Nota-se que os planos (mesmo considerando que essas tabelas estejam desatualizadas) detinham em 95 um mercado consumidor de 36 milhões de usuários e um faturamento de aproximadamente $\mathrm{R} \$ 10,32$ bilhões. Vale destacar que $85 \%$ dos planos eram coletivos, ou seja, comercializados junto às empresas (op.cit).

Cada segmento apresenta especificidades quanto ao produto oferecido e as formas de comercialização. Esse mercado apresenta, portanto, um alto grau de diferenciação de produto e, desse modo, seus produtos são heterogêneos. Tal diferenciação do produto acaba refletindo também em diferenças quanto ao porte patrimonial, financeiro, capacidade instalada de serviços, inserção na estrutura produtiva etc. das empresas médicas. Essas diferenças, entretanto, não descaracterizam o mercado, tendo em vista que todas essas modalidades de assistência médica suplementar vendem mercadorias que são substitutas entre sí.

Torna-se cada vez mais necessário analisar minuciosamente o imbricamento financeiro entre os planos de saúde e os gastos públicos em saúde (elemento central, em nosso caso, para diferenciar os capitais privados desse mercado). Fica aqui implícito que um quadro conceitual mais preciso sobre a definição do mercado de serviços de saúde será, no momento, abstraído.

Nessa perspectiva, uma caracterização ainda que precária desse mercado, baseando-se na designação de um setor não-autônomo e de um setor autônomo em relação aos gastos públicos, é fundamental para o desenvolvimento desse trabalho.

Caracterizamos o mercado de serviços de saúde em dois grandes grupos. O primeiro grupo está circunscrito ao que se denomina de setor privado contratado ${ }^{7}$. O grupo está composto por prestadores de serviços de saúde que mantêm uma relação direta de compra e venda com o Estado. Após a implantação do SUS, o acesso a tais serviços independe de qualquer contribuição monetária. $\mathrm{O}$ segundo grupo está circunscrito ao que se denomina de seguro-saúde privado ou setor privado autônomo ${ }^{8}$. Esse grupo está composto pelas seguradoras de saúde, as empresas de medicina de grupo, as cooperativas médicas e os serviços de saúde próprios das empresas. No entanto, ao contrário do grupo anterior, o acesso a tais serviços pressupõe contribuição monetária direta.

Em outras palavras, esse mercado abrange, então, dois grandes ramos capitalistas: um ramo cuja dinâmica de acumulação não é autônoma em relação aos gastos públicos em saúde (o setor contratado) e outro ramo (ou ramos) onde tal dinâmica é autônoma frente a esses gastos.

Tais ramos autônomos podem ser definidos segundo sua especificidade no mercado capitalista (seguro-saúde privado) ou segundo o caráter da sua relação com os gastos públicos em saúde (setor privado autônomo). 
A noção de seguro-saúde privado está associada, especificamente, à criação de mecanismos de financiamento orientados para garantir o consumo dos serviços médico-assistenciais mediante transações monetárias. Esses mecanismos supõem uma contribuição prévia do segurado para a garantia do recebimento de tais serviços:

"Assim, entende-se por seguro-saúde privado todo e qualquer mecanismo de financiamento privado de consumo de serviços de saúde contemplando o pagamento de prestações a uma empresa, que se obrigará a fornecer assistência médica ou reembolsar seus gastos, mediante contrato firmado entre as partes" (Andreazzi 1995:11).

Essa noção também pode ser derivada de uma análise que tente diferenciar o seguro social do seguro privado. Tais diferenças repousam fundamentalmente no caráter obrigatório e assistencial do seguro social, que por ser desenvolvido pelo Estado, não seleciona riscos e não objetiva lucros. Do lado do seguro privado, o que o diferencia é o reconhecimento do direito do segurado em receber um benefício tendo em vista a ocorrência de um dano (op. cit.: 43).

A noção de setor privado autônomo, por outro lado, decorre propriamente da tentativa de diferenciar esse mercado tendo por base o caráter de autonomia dos seus ramos em relação aos gastos públicos em saúde por:

“(...) considerar-se que os 'planos de saúde' (...) vêm reduzindo continuamente a centralidade do gasto público como elemento de sustentação financeira do sub-sistema privado de saúde" (Conill 1993:100).

No entanto, essa noção é usualmente apropriada para designar uma autonomia financeira do setor privado autônomo em relação ao Estado:

“(...) elementos (...) indicam uma crescente autonomia do setor privado vis-à-vis o Estado na década de 80, em função do fortalecimento de novos mecanismos de financiamento (os planos de saúde) capazes de viabilizar o acesso ao sistema privado por parte das camadas médias, à margem da intervenção da política social" (Faveret Filho \& Oliveira 1990:258, grifo do autor).

De outro ângulo, essa idéia acerca do que é autônomo decorre da evidente conformação de uma oferta diferenciada dos serviços de saúde e da decrescente dependência do setor prestador no tocante aos gastos públicos em saúde:

"o sistema de atenção médica, de forma gradativa, foi se integrando à dualidade da economia brasileira, com os seus segmentos — o setor privado e o público — se especializando em 
camadas distintas da população. $O$ primeiro se dirigiu, então, para aquele setor da sociedade capaz de enfrentar os altos custos (...) do tratamento médico. As altas taxas de lucro assim obtidas vão permitir ao sub-setor privado do SPMS (...) uma decrescente dependência econômica e financeira do Estado (...) (verificando-se) a (...) consolidação das práticas capitalistas do SPMS, com o Estado aparecendo como um ator coadjuvante do enredo engendrado pela rede privada na área da assistência médica" (Vianna 1987 apud Werneck Vianna 1994:20).

Além do mais, aproveitando a oportunidade...

“(...) a rigor, como a clientela da medicina privada utiliza os serviços mais onerosos do SUS - sem querer entrar na discussão do mérito da legitimidade deste uso - do ponto de vista da empresa médica, o gasto público estaria também promovendo 'à certa distância' o seu ritmo de acumulação. (...). Poderíamos então dizer que este setor padece de uma espécie de 'complexo de Édipo': não se libertou completamente nem mesmo do instrumento que possibilitou a sua gestação, os gastos públicos em saúde" (Reis 1997).

No entanto, apesar do setor privado autônomo ser quase autônomo em relação aos gastos públicos em saúde, ele não independe do Estado, devido às suas articulações com o padrão de financiamento público. Dessa forma, seria o grau de dependência em relação ao padrão de financiamento público o elemento diferenciador do mercado de serviços de saúde no que tange ao seu relacionamento com a esfera política.

Assim, parece-nos importante discutir como a expansão do setor privado autônomo foi se realizando mediante tais incentivos, tentando observar a correlação entre a constituição histórica desse setor e uma política deliberada de sucateamento dos serviços públicos de saúde.

Esse quadro nos coloca ainda duas questões adicionais: a) por que essa fração específica do capital de alguma forma não consegue se desvincular dos recursos financeiros do fundo público para se expandir? b) se tal setor não é autônomo em relação ao padrão de financiamento público, ou se quisermos, apresenta uma autonomia restrita, quais seriam as implicações na conformação do mix público/privado no Brasil?

\section{As raízes históricas: a expansão dos planos de saúde}

O surgimento do setor privado autônomo coincide com a instalação das indústrias transnacionais de bens de consumo duráveis do governo Kubitscheck (1956-1960), em especial, as indústrias automobilísticas do 
ABC paulista. $\mathrm{O}$ padrão de industrialização engendrado, nessa região, exigiu das empresas o treinamento, a assiduidade e a integração da força de trabalho, visando à coesão ideológica e ao aumento da sua produtividade. Desse modo, as “(...) empresas passam a se interessar em ter sob seu controle a assistência médica dos seus empregados (...)" (Medici 1992:7).

Esse surgimento só foi possível graças à existência de mecanismos de financiamento privado desvinculados do financiamento direto da previdência social. Fomentado pela demanda dos serviços privados de saúde, capital e trabalho financiaram o provimento da assistência médica da força de trabalho, abrindo espaço ao crescimento das empresas de medicina de grupo e dos departamentos de saúde das empresas (Cordeiro 1984; Bahia 1991) ${ }^{9}$.

Foi, entretanto, a partir do golpe militar de 1964, que as mudanças operadas no âmbito da medicina previdenciária acabaram promovendo uma acelerada expansão do setor privado autônomo. Como pano de fundo, a reforma administrativa de 1965, implementada pelo Decreto-Lei 200, que viabilizou as bases institucionais à contratação de empresas na execução de programas e projetos sob a responsabilidade do Estado. Na mesma direção, o Plano de Ação para a Previdência Social (PAPS), em 1966, sinalizou a preferência pelo estabelecimento de convênios com as modalidades privadas de atenção médica:

“o PAPS estabeleceu que a manutenção dos serviços próprios deveria ser provisória enquanto ainda não fosse sistemática a prestação da assistência médica por serviços de terceiros observados (...) a seguinte ordem prioritária: a) serviços médicos das empresas filiadas ou mantidas por órgãos classistas; b) serviços médicos privados, sem finalidade lucrativa; e c) demais serviços privados" (Cordeiro 1984).

Esse processo ganhou velocidade com a criação do Instituto Nacional da Previdência Social (INPS), em 1967, baseando-se na unificação dos Institutos de Aposentadoria e Pensão (IAP's) que impulsionara o emergente setor privado autônomo.

Sua estruturação provocou a eliminação progressiva da gestão tripartite entre União, empregadores e empregados das instituições previdenciárias, despolitizando a estrutura de poder construída a partir da Revolução de 30. Igualmente, provocou uma acentuada centralização financeira nas mãos do governo central, ampliada pelo aumento da contribuição previdenciária. Ademais, impediu os trabalhadores de participarem do processo decisório sobre a sua assistência médica (Fleury \& Oliveira 1985). 
Como a unificação baixou o padrão de atendimento de serviços de saúde, as empresas e as categorias, que ofereciam anteriormente serviços de melhor qualidade, identificaram nas empresas médicas a possibilidade de manter o bom padrão de atendimento conquistado. A unificação ampliou a cobertura, passando a incorporar trabalhadores com carteira assinada não cobertos pelos antigos IAP's. Essa ampliação estimulou a demanda pelos serviços privados de saúde, já que não houve a correspondente expansão da rede pública (Medici 1992).

Assistiu-se, posteriormente, a generalização da contratação dos serviços de saúde prestados pelo setor privado autônomo. Essa generalização foi também resultante da regulamentação do seguro privado, por meio do Decreto-Lei 73 em 1966 e da própria unificação dos IAP's:

"a análise da conjuntura econômica e política da época, chama a atenção a simultaneidade da edição dos Decretos-Lei 73 e 66/67 que unificou os Institutos de Aposentadoria e Pensões criando o INPS, em pleno recesso do Congresso Nacional. $\mathrm{O}$ fato parece demonstrar a existência de uma intencionalidade por parte das autoridades da época em dar um caráter de complementaridade ou ainda compensador, através do setor privado, de possíveis perdas de benefícios por parte de categorias de trabalhadores agora nivelados num mesmo tratamento pelo novo órgão. (...) De qualquer modo, a simultaneidade dos decretos sinaliza uma abertura do mercado para o seguro privado, com o mercado potencial representado pela sobra dos insatisfeitos pelo regime de unificação do seguro social" (Andreazzi 1995:83).

Segundo Cordeiro (1984), a criação dos convênios INPS/empresa, regulamentado pelo Decreto 81.784 de 1967, acabaram igualmente por fortalecer aquela generalização. Tais convênios eram articulados entre as empresas médicas e as empresas em geral, possibilitando às primeiras um dinamismo próprio, independentemente do financiamento direto do Estado. O que não significava dizer que não tenha sido, mais uma vez, estabelecido uma relação indireta com o fundo público:

“o convênio-empresa previa a restituição pelo INPS à empresa (e sindicatos), de um valor fixo mensal, por empregado, correspondente a $5 \%$ do maior salário mínimo vigente, reservando-se àquele o direito de fiscalizar os padrões de atendimento. A empresa obrigava-se a dar atendimento integral aos funcionários. A partir de 1969, o INPS passa a arcar com o atendimento mais caro dos convênios (...)" (op. cit. 1995:90). 
Em 1974, tendo por base a implementação do Plano de Pronta Ação (PPA), abre-se novamente um nova fronteira de acumulação ao setor privado autônomo:

“a partir de 74, com o Plano de Pronta Ação (PPA) que promoveu a ampliação do acesso aos serviços pela população das áreas metropolitanas, tornaram-se economicamente viáveis as empresas médicas emergentes. A concorrência dos interesses de grupos médicos com os das grandes empresas industriais e comerciais facilitou o desenvolvimento dos convênios-empresa e das organizações de medicina de grupo, que não pararam de crescer (...)" (Werneck Vianna 1989:20-21).

Agrega-se a isso que a expansão desses convênios intensifica-se sobretudo em função dos incentivos fiscais que foram permitidos para a operação de tal modalidade de atenção médica:

"as normas reformuladas para o custeio e homologação dos convênios-empresa entre 1974 e 1975 (...) permitiam a dedução de todos os gastos das empresas com esta finalidade do imposto de renda" (op. cit. 1994:28-29).

Em meados da década de 70, então, constituiu-se um modelo de atenção médica funcional para o emergente setor privado autônomo. Essa constituição esteve associada à tecnificação do ato médico, à própria constituição das empresas capitalistas do setor e ao assalariamento dos profissionais de medicina (Cordeiro 1984;1985 e Vianna et alli 1987). Paralelamente, as empresas, em geral, passaram a oferecer tais serviços à força de trabalho enquanto salário indireto. Não é à toa que a “(...) saúde passou (...) a ser vista como um bem de consumo. Especificamente um bem de consumo médico" (Luz 1991:82) ${ }^{10}$.

Era o chamado modelo assistencial estatal-privatista (op.cit. 1991) que se sustentava numa concepção de saúde curativa, individual, assistencialista e com alto grau de complexidade tecnológica, tendo o hospital como locus centraldo processo de produção dos serviços médicos:

"as modificações tecnológicas na área de apoio diagnóstico e terapêutica, ocorridas nos países desenvolvidos a partir da década de 50, introduziram um novo ramo na economia: a indústria de equipamentos e medicamentos. Isto modifica substancialmente a prática médica que passa a se utilizar, de forma crescente, de recursos tecnológicos sofisticados. O médico é separado dos seus instrumentos de trabalho, as atividades concentram-se cada vez mais em hospitais, tende-se para o assalariamento e há encarecimento dos atos médicos" (Andreazzi 1995:2) ${ }^{11}$. 
Em 1975, o financiamento direto a juros negativos para a construção de hospitais privados e para compra de equipamentos pelo Fundo de Apoio ao Desenvolvimento Social (FAS), operado pela Caixa Econômica Federal (Noronha \& Levcovitz 1994), terminou ampliando a oferta e permitindo a verticalização da produção de serviços das empresas médicas:

"as políticas de compra de serviços de saúde à iniciativa privada e o acesso a financiamentos subsidiados junto ao FAS permitiram uma acelerada expansão da capacidade instalada da AMIL" (Bahia 1991:70).

Em fins da década, os primeiros sinais da recessão econômica e da crise financeira da previdência provocaram um duplo efeito ${ }^{12}$ :

“(...) o desaparecimento progressivo do INAMPS enquanto prestador/financiador da assistência médica dos trabalhadores (devido à) redução da qualidade dos serviços pelo esmagamento dos preços pagos ao setor privado/contratado e a extinção dos convênios INAMPS/empresa, INAMPS/sindicato (...)" (Medici 1992b:9).

Essa deterioração progressiva dos valores dos serviços custeados pelo INAMPS, o que não era surpresa diante da escalada inflacionária dos anos 80, , “...) permitiu a ruptura unilateral, por parte dos hospitais, de vários convênios e contratados destes estabelecimentos com o INAMPS" (op. cit. 1992b:11).

A ruptura indicava que, dada a crise financeira da previdência, alguns hospitais privados lucrativos optaram por se relacionar com as modalidades de atenção médica complementar. Tal ruptura deixara igualmente evidente uma crise provocada pelos interesses antagônicos entre o INAMPS, os hospitais lucrativos e as empresas capitalistas, colocando a necessidade de buscar soluções para assistência médica dos seus trabalhadores (e dependentes) em último lugar no âmbito das empresas.

No entanto, apesar desses fatores no contexto da fragilização do INAMPS, a extinção dos convênios INAMPS/empresa não inibiu o crescimento do setor privado autônomo:

“(...) a parceria estava desfeita, pois nessa altura nem os grupos médicos nem as empresas precisavam mais do INAMPS. Uns porque já haviam conquistado substancial fatia do mercado, vendendo diretamente seus serviços a indivíduos ou firmas; as outras porque preferiam dispensar o controle exercido" (Werneck Vianna 1994:32).

Desse modo, no início dos anos 80, devido à crescente deterioração dos serviços públicos de saúde, as empresas em geral e as classes médias precisavam dos serviços financiados e prestados por tal setor: 
"a clientela potencial dos convênios-empresa e planos de saúde (operários qualificados, assalariados com rendas médias e altas, profissionais liberais etc.) crescera e se diversificara na esteira da modernização econômica. Seres emergentes, que desconheciam as 'vantagens' antes oferecidas pelo corporativismo estatizante dos IAPs, haviam entrado em cena. Assim, nos anos 70, formara-se uma significativa demanda por serviços médicos massificados de boa qualidade. Ou o Estado os fornecia - e para isso faltava a voz que o autoritarismo calara - ou o mercado engendrava a saída" (op.cit. 1994:26).

Esse consumo seria fortemente induzido pela possibilidade de deduzir do imposto de renda de pessoas físicas e jurídicas:

“(...) um fator adicional veio a pesar: a possibilidade de deduzir despesas com saúde do imposto de renda. Esse dispositivo, pouco lembrado, implantou-se com as sucessivas reformas fiscais realizadas (o Código Fiscal Nacional de 1966, a Constituição de 1967, o Decreto-Lei 200, os 11 decretos promulgados no rastro do AI-5) e contribuiu para consolidar a imagem do cidadão como 'pessoa física', vale dizer, como um contribuinte integrado ao universo do consumo individualizado - inclusive, de serviços médicos" (op. cit. 1994:26-27).

A tabela a seguir tenta apontar, entre os anos de 1979 e 1984, os gastos de saúde das famílias abatidos no imposto de renda das pessoas físicas ${ }^{13}$.

Tabela 3: Gastos com saúde das famílias nas declarações de imposto de renda da pessoa física. Brasil, 1979-1984

\begin{tabular}{l|c|c|c}
\hline Anos & $\begin{array}{c}\text { Gastos de saúde } \\
\text { das famílias }\end{array}$ & $\begin{array}{c}\text { \% sobre o gasto } \\
\text { federal em saúde }\end{array}$ & $\begin{array}{c}\text { \% sobre o gasto } \\
\text { do INAMPS }\end{array}$ \\
\hline 1979 & $1.125,4$ & 29,0 & 35,1 \\
\hline 1980 & 932,9 & 24,2 & 28,6 \\
\hline 1981 & 757,0 & 18,0 & 25,1 \\
\hline 1982 & 835,5 & 18,2 & 27,2 \\
\hline 1983 & 733,8 & 22,7 & 28,6 \\
\hline 1984 & 617,2 & 18,1 & 22,6 \\
\hline
\end{tabular}

Fontes: Ministério da Fazenda / Centro de Informações Econômico-Fiscais, apud Medici (1990b). 
Num primeiro momento, então, constatou-se que o Estado brasileiro antecipou e ampliou o padrão de acumulação do mercado dos serviços de saúde, fundamentalmente do setor privado tradicional, cuja rede de serviços tornou-se dominante. Assim, favoreceu os contratos e convênios com esse mercado e com os médicos credenciados, em detrimento das atividades de saúde pública (Braga \& Góes de Paula 1986).

Paralelamente, o Estado brasileiro, em busca de maior legitimidade, universalizou gradualmente o acesso àqueles serviços e dessa forma teve que transferir recursos crescentes a esses setores.

Criou-se uma dupla relação de dependência: uma dependência do Estado com o setor privado contratado, no que diz respeito à utilização da rede de serviços, e uma dependência desse setor em relação aos gastos públicos em saúde.

No que tange então ao financiamento da medicina previdenciária, ela tornou-se extremamente funcional para a ordem capitalista: por não desviar recursos fiscais do circuito acumulação-realização e por antecipar inclusive as necessidades de ampliação do emergente setor privado autônomo.

Ao longo dos anos 80, as classes médias passam a recorrer crescentemente aos planos de assistência médica, e os trabalhadores exigiram de suas empresas convênios desse tipo como diferencial de salário. Esse mercado autônomo consolida-se com a expansão dos planos de saúde, apresentando um certo grau de autonomização financeira face aos gastos públicos em saúde, embora tenha sido evidente o apoio do Estado na constituição de tal setor.

Nesse quadro, os incentivos governamentais propiciados ao setor privado autônomo permitem questionar seu caráter em relação ao padrão de financiamento público. Na verdade, a autonomia de tal setor frente aos gastos públicos em saúde é um elemento insuficiente para caracterizar sua autonomia financeira em relação ao Estado.

\section{O fundo público e os planos de saúde: um esboço teórico}

As possibilidades de avanço da produtividade do trabalho no setor saúde seriam no mínimo restritas em relação às demais atividades econômicas. Existiria assim uma relação inversa entre conhecimento médico e a produtividade do trabalho nos serviços de saúde. Nessa perspectiva, ao se observar o tratamento individual como o produto dos serviços médicos, a expansão do conhecimento médico poderia significar a dedicação de mais tempo de trabalho por unidade de produção (Bayer \& Leis 1986) ${ }^{14}$. 
Paralelamente, o processo de trabalho na produção dos serviços médicos seria (apenas em parte) passível dos procedimentos usuais de fragmentação, no sentido de sua decomposição em tarefas a serem executadas por trabalho desqualificado, levando à desvalorização do valor de troca do trabalho empregado (Braverman 1981:359-378). Em outros termos, reduzindo relativamente o salário nominal. Pelo contrário, mesmo no caso dos avanços técnicos obtidos por meio da mecanização, os equipamentos tenderiam a gerar novas especializações complexas e não a substituir trabalho qualificado por trabalho simples; a não ser em processos de trabalho de fluxo contínuo:

“a tecnologia em saúde só tem permitido a redução do emprego quando é aplicada em processos de trabalho de fluxo contínuo. O mesmo não se aplica em processo de trabalho de fluxo descontínuo, como é o caso de consultas e cirurgias. Assim, dado o seu baixo impacto na redução do emprego, a tecnologia médica não elimina e algumas vezes intensifica o caráter labor-intensive do setor. Com isso, os custos associados a um setor que incorpora cada vez mais tecnologia em equipamentos caros de diagnóstico e terapia tendem a crescer vertiginosamente ao longo do tempo" (Medici 1990a:9).

Em termos capitalistas, então, os serviços médicos teriam que apresentar um crescimento em seus preços, em geral, devido à pressão altista dos salários decorrentes do caráter de uso intensivo da mão-de-obra médica e, também, devido à pressão altista decorrente da incorporação e diferenciação de tecnologia ${ }^{15}$, principalmente os meios de complementação diagnóstica - como a tomografia computadorizada, a imagem por ressonância magnética etc. (Marques 1991:37).

$\mathrm{Na}$ verdade, o próprio modelo médico-assistencial hegemônico acentuaria a incorporação e diferenciação dessa tecnologia. O padrão de competição desse mercado enfatizaria a importância do fator tecnológico na resolutividade dos problemas de saúde. Assim, as políticas de marketing desenvolvidas pelos meios de comunicação de massa, notadamente a televisão, estariam favorecendo a propensão a consumir seus serviços, cristalizando o moral hazard (abuso do usuário).

Esse quadro ampliaria os custos fixos das empresas médicas e, desse modo, pressionaria seus preços. Além do mais, os médicos também induziriam seus pacientes a consumir exames diagnósticos, o que, por sua vez, encareceria ainda mais os serviços. Daí o aparecimento de instrumentos gerenciais como o managed care para frear tal consumo.

De outro ângulo, na média, a inovação dos insumos tecnológicos não atenderia ao modelo clássico schumpeteriano ${ }^{16}$, qual seja, da destruição criadora. Poder-se-ia observar que a criação de um tomógrafo computadorizado não destrói a utilização do raio-X. 
Isto não significaria dizer que, futuramente, modificações técnicoprodutivas, somadas a um maior controle sobre a força de trabalho médica, não venham a negar essa afirmação. Sobretudo se, na era da globalização, o capital financeiro, que vem funcionando como um ersartz (substituto) do fundo público, expanda-se no setor saúde (como na recente associação do Excel/Cigna na compra da Golden). A rigor, esse deslocamento do capital financeiro ao mercado de proteção social no Brasil tem início em fins da década de 60 no interior da economia brasileira (Andreazzi 1991).

$\mathrm{E}$, finalmente, a tendência do crescimento dos preços dos serviços médicos se daria devido à pressão altista decorrente dos custos financeiros provocados por elevadas taxas de juros, numa estratégia de política antiinflacionária. Tendo em vista que a adoção do Plano Real impediu que as empresas médicas continuassem a obter vantagens competitivas por meio da ciranda financeira (floating).

Posto isso, os planos teriam que viabilizar necessariamente sua reprodução, acompanhando a expectativa geral de lucros pelo aumento de preços acima da média do mercado (Vogt 1980). Evidências empíricas demonstram que a inflação do setor saúde tem sido tradicionalmente mais alta do que a média dos demais setores (Medici 1991a:11).

No longo prazo, a necessidade dos serviços médicos aumentaria (por exemplo, com o aumento da expectativa de vida ou da conscientização dos direitos sociais). Juntamente com o avanço da capacidade teóricoprática da medicina, essa necessidade crescente tenderia a torná-los economicamente inacessíveis (devido o aumento de preços), se mantidos de forma estritamente capitalista.

Tal tendência no preço dos serviços médicos poderia apontar a seguinte contradição para o capitalista do setor: ou haveria uma contração do mercado atendido, ou ainda, a própria impossibilidade de acompanhar o ritmo da obsolescência da tecnologia incorporada ao ato médico (Vianna 1987:34-35) determinaria uma minimização daquela contração, dado que se poderia operar com custos e preços menos elevados, mas, no entanto, com menores possibilidades de competição no mercado. Assim, como auferir economias de escala (reduzir custos unitários) por cada unidade (tratamento individual em si e para si) adicional produzida?

Para ilustrar esse fato, uma matéria públicada pela revista Suma Econômica (1992:42) afirma que até nos Estados Unidos “(...) quando um novo aparelho ou equipamento médico acaba de ser pago, ele já está superado, obrigando a constantes renovações e acabando por encarecer ainda mais os custos da assistência médico-hospitalar".

Ademais, o padrão de concorrência das empresas do setor saúde situa-se dentro da lógica da estrutura de mercado do capitalismo brasileiro, cujos traços apresentam um perfil claramente oligopolista (Possas 1985) ${ }^{17}$. 
Em que pese que tal configuração seja relevante para o processo competitivo e de formação de preços das empresas médicas, esse fato não modificaria a natureza crescente dos custos, senão o grau de manobra que essas empresas possuem frente a essa tendência econômica.

De outro ângulo, a concorrência intercapitalista entre os planos de saúde é também afetada por determinada regulamentação jurídica especí fica e, em especial, intimamente vinculada à disposição organizacional dos serviços públicos: sabe-se que o perfil da oferta de boa parte das empresas médicas é forjada com base no perfil de oferta do SUS: sua localização geográfica, seu nível de complexidade, as nosologias tratadas etc.

As tendências futuras do mercado dos planos estão associadas à rigidez dos custos crescentes na competitividade das empresas à luz de determinada regulamentação no contexto da supremacia do capital financeiro no capitalismo monopolista e transnacionalizado. A possibilidade da abertura do mercado às seguradoras transnacionais, supostamente para aumentar a competição, demonstra a disposição do governo FHC em seguir a sua real politic, ao considerar a burguesia nacional, na fase da globalização econômica e financeira, como sócia menor e dependente (Fiori 1994).

Neste contexto, as empresas médicas poderiam depender de recursos financeiros crescentes do padrão de financiamento público, tendo em vista os custos crescentes (Braga \& Góes de Paula 1986; Medici 1991), na expectativa da garantia de suas condições de rentabilidade ${ }^{18}$. E, por isso, as condições de viabilidade econômica dessas empresas seriam sinalizadas em última instância pela ação do Estado, a respeito das dobras gerenciais e médico-assistenciais que permitem que os planos operem com menores custos, dada a mesma qualidade de atenção.

O Estado agiria, por meio do fundo público, no sentido da reconstituição das condições de rentabilidade do setor privado autônomo, pelos mecanismos de subvenção:

"Essa intervenção do Estado representaria uma das contratendências em relação à baixa tendencial da taxa de lucro (...). Mas, além dessa questão econômica mais direta, esse padrão de intervenção constitui um processo de transformação capitalista das próprias políticas sociais. Esse processo se manifesta pela privatização ou pelo apoio dado pelo Estado à rentabilização dos empreendimentos privados de saúde" (Andreazzi 1995:27).

Assim, a publicidade enganosa, as exclusões de patologias, a expulsão dos idosos, os tetos de utilização, os prazos de carência, os conflitos distributivos na relação capital/trabalho nas empresas médicas etc. existentes no setor não seriam elementos que corroboram a hipótese dos custos 
crescentes. Elas apenas indicam que tendo em vista a baixa produ-

tividade do trabalho, além das dificuldades de ganhos de escala, esses expedientes seriam utilizados como forma de aumentar o mark-up ${ }^{19}$ das empresas médicas. Por isso que a discussão do projeto de lei que regulamenta o setor é tão polêmica, porque em suma, regulamentação ali, poderia significar regulamentar os preços e, portanto, a taxa de lucro dos capitalistas do setor.

Isso colocaria o Estado frente ao dilema de manter — sobretudo à PEA, por razões políticas e sociais, determinadas atividades economicamente não rentáveis por meio de mecanismos de subvenção (mantendo sua forma privada) ou então, estatizando-as (radicalizando os mecanismos de subvenção (Bayer \& Leis 1984:114).

Essas características de natureza econômica e política atingem em cheio os serviços de saúde capitalistas, caso não sejam subsidiados pelo padrão de financiamento público. A hipótese central desse trabalho afirma que se os custos do setor são crescentes (seja devido à baixa produtividade do trabalho, seja devido à baixa capacidade de auferir economias de escala, responsáveis pelos elevados custos unitários das empresas médicas) o fundo público ${ }^{20}$ tornar-se-ia um pressuposto fundamental para a rentabilidade econômica destes capitais particulares.

\section{Considerações finais}

\section{O caráter da regulamentação dos planos de saúde}

A existência de mecanismos de subvenção, além de revelar uma interação entre o padrão de financiamento público e a dinâmica de acumulação do setor privado autônomo, poderia apontar também o potencial de atuação do Estado, dado que detém recursos financeiros, políticos e organizacionais essenciais para a lógica de reprodução dos planos de saúde.

No entanto, a hegemonia na organização do sistema de saúde e na orientação das políticas de saúde é forçosamente praticada pelo mercado.

Identificamos aqui o paradoxo dos planos: se por um lado, ele apresentaria uma dificuldade de autonomia capitalista, em última instância, entretanto, comandaria o processo de (re)organização dos serviços de saúde e da própria orientação das políticas de saúde no Brasil.

Esse paradoxo, por sua vez, deixa margem para a atuação do Estado, já que ao deter recursos financeiros, políticos e organizacionais essenciais para a lógica de reprodução daquele mercado, o mesmo poderia, por meio das políticas de saúde, regulamentar efetivamente o mercado dos serviços de saúde e, em especial, o setor privado autônomo. 
Para exercitar essa tarefa, seria necessário o fortalecimento do setor público de saúde para competir (disputar hegemonia) com os planos de saúde. O Estado em sua dimensão econômica, político-jurídica e organizacional possui uma capacidade real, concreta, de regular ${ }^{21}$ as frações do capital organizadas no setor saúde, o que por sua vez, poderia estabelecer um círculo virtuoso em relação ao setor público de saúde (SUS), reforçando a regulamentação.

É possível, entretanto, que a regulamentação ${ }^{22}$ dos planos de saúde permita, tal como vem sendo conduzida, criar as bases institucionais para a internacionalização e oligopolização acelerada do mercado, tornando o seu processo de formação de preços menos suscetível à regulação pelo Estado. Ou seja, definir-se-ia um tipo de regulamentação para corrigir as falhas do mercado (como reconhece a teoria econômica neoclássica) vis-à-vis às externalidades e assimetrias do mercado (Maynard 1996; Nunes 1996). Ou seja, em detrimento de um tipo de regulamentação que efetivamente regule a taxa de lucro e garanta a qualidade e a ética na prestação dos serviços médicos à população.

\section{O mercado de planos de saúde: o problema vira solução?}

Corroborando a idéia de Andreazzi (1992), constatamos que a principal contradição na relação público/privado na área de saúde no Brasil não se dá em relação à prestação de serviços, mas sim no tocante ao nível do financiamento da atenção à saúde.

Esse processo expresso nos incentivos governamentais resultou em perdas significativas de recursos públicos que poderiam ter representado um aumento substancial no orçamento estatal em saúde.

Como outrora comentou o atual Ministro da Saúde José Serra:

"Hoje, o pobre acaba financiando a saúde de quem tem mais dinheiro. Os recursos que deixam de ser arrecadados com os abatimentos de imposto de renda poderiam reforçar o orçamento da saúde (...). Sei que a proposta prejudica a classe média, mas está na hora de tirar de quem tem mais para dar a quem tem menos — disse o deputado, que calcula em $\mathrm{R} \$ 900$ milhões por ano o que a saúde teria com a mudança" (O Globo 11/8/95).

Relacionamos de forma condensada os incentivos governamentais acionados pelo Estado brasileiro ao setor privado autônomo tanto na fase da sua expansão quanto na fase da sua consolidação:

- permitindo às empresas que as contratavam descontar ou devolver parte de contribuição previdenciária, principalmente baseando-se nos 
convênios INPS/empresa (que também definiam que os atendimentos mais caros deveriam ser prestados pelo Estado);

- estabelecendo normas que abriram, no campo jurídico, um espaço favorável à sua expansão;

- financiando a juros negativos a construção de instalações físicas hospitalares e a compra de equipamentos médicos, com longo prazo de carência;

- viabilizando o consumo dos serviços privados de saúde, pela dedução do imposto de renda de pessoa física e jurídica, dependendo da orientação da política econômica;

- considerando, enquanto estabelecimentos filantrópicos, diversas empresas médicas que desempenhavam nitidamente atividades lucrativas. Isso implicou em uma série de privilégios no campo fiscal;

- prestando os serviços de saúde de alto custo, como as doenças de longa duração e as cirurgias de alta complexidade, para a clientela da medicina privada.

Na década de 90, a demonstração mais visível de como o fundo público opera a viabilização do consumo dos serviços privados de saúde é a dedução do imposto de renda de pessoa física e a subtração do imposto a pagar das empresas sobre o lucro líquido, já que os gastos com assistência médica são considerados despesas operacionais.

$\mathrm{Na}$ verdade, embora o setor autônomo estabeleça um relacionamento diferente com o Estado, em relação àquele efetuado pelo setor privado contratado (não-autônomo), não se pode obscurecer a unidade que existe entre o ramo contratado e o ramo autônomo: ambos retiram recursos financeiros do fundo público para se reproduzirem de modo capitalista, seja pelo financiamento direto, seja pela renúncia do governo de parte de suas receitas fiscais, com base nos incentivos e subsídios.

Essa constatação nos leva à seguinte reflexão: o conceito de setor privado autônomo (construído baseando-se na evidência da independência desse setor em relação aos gastos públicos em saúde) é usualmente apropriado para evidenciar uma relação de autonomia financeira no que se refere ao Estado. Essa associação pode conduzir ao seguinte equívoco: ao não perceber que o setor privado autônomo mantém uma articulação com o padrão de financiamento público, ficaria obscurecida a dependência desse setor em relação ao Estado.

Esse quadro vem provocando a fragilização crescente do setor público de saúde, a um só tempo, prisioneiro do caráter privatista das políticas de saúde das últimas décadas ${ }^{23}$ e das estratégias de expansão dos planos de saúde. 
1 Sabe-se que o lucro líquido das empresas é subtraído pelas despesas operacionais das mesmas com os gastos da assistência médica dos seus trabalhadores. Assim, esse abatimento acaba, por um lado, reduzindo o lucro líquido a pagar das empresas na forma de impostos e, por outro, reduzindo o valor da contribuição social sobre o lucro específico das empresas paga ao Orçamento da Seguridade Social (OSS) que, nos últimos anos, junto com o COFINS, vêm financiando majoritariamente os gastos públicos federais em saúde.

2 Esse privilégio caiu com o novo projeto de regulamentação.

3 Ver Faveret Filho e Oliveira (1988).

4 Estimativa realizada por Solon Magalhães Vianna (1998), Consultor do Ipea/Cepal, mimeo.

5 No entanto, vale destacar que cada vez mais essa modalidade organiza-se tomando por base sistemas de pré-pagamento para se proteger dos eventos de alto custo. Além do mais, embora sem finalidades lucrativas, a autogestão começa a vender planos no mercado assim como as operadoras.

6 A economista inglesa Joan Robison definiu, grosso modo, como mercado: a demanda por um grupo de mercadorias que são substitutas próximas de si (apud Guimarães 1981:33).

7 As instituições filantrópicas, embora não tenham declaradamente fins lucrativos, podem exercer contratos, convênios e credenciamentos com o sistema público e com o setor privado autônomo (inclusive vender planos de saúde), principalmente as instituições cujas clientelas são abertas e universais.

8 O médico-empresário e o profissional liberal fazem também parte do segmento do setor privado autônomo. Seus serviços são financiados pelo desembolso direto da renda dos consumidores (esses atores não serão analisados neste trabalho).

9 Vale lembrar que, desde já, a dinâmica de acumulação desse setor necessitou da participação do fundo público: "o governo apoiou esta iniciativa e compreendia o alcance social das empresas de medicina de grupo e concedeu aos empresários que assim decidissem dar assistência médica ou se responsabilizassem pela assistência médica a seus funcionários, dar desconto ou devolver parte da contribuição que era prestada na época ao INPS, para que esse valor relativo à assistência médica fosse dado em serviço médico aos funcionários e seus dependentes" (Almeida 1994:1-2).

10 De outro ângulo, analisando a conjuntura política da época, pode-se dizer que "fatores ligados à política social, neste período, foram fundamentais para redirecionar o estilo de atuação da Previdência Social. Com o advento da crise econômica, o regime militar tem enfraquecidas suas bases de sustentação política, cresce a insatisfação popular, o que se manifesta sob a forma de derrotas eleitorais. O regime passa a usar a política previdenciária, cada vez mais universalizada, como resposta às demandas populares, criando ao mesmo tempo mecanismos que permitissem o atendimento diferenciado aos setores ligados à economia formal urbana, no que diz respeito à política de reparação da força de trabalho e, além disso, estimula mecanismos que, viabilizando a privatização, acabam permitindo o consumo diferenciado de serviços de saúde pela classe média" (Andreazzi 1995:130).

11 A autora vai mais longe: "a consequiência mais dramática deste fato é que o ato médico, a prestação do serviço, passa a ser o elemento que irá desencadear a realização da série de mercadorias produzidas pelas indústrias que se criam a partir daquelas transformações tecnológicas. Historicamente, é recente este fato do serviço de saúde viabilizar a 
acumulação industrial específica de um setor que gira em torno dele passando de uma forma de organização artesanal à outra, corporativa, criando as bases de seu empresariamento" (op.cit. 1995:34).

12 Na verdade, “(...) os valores do convênio empresa são congelados a partir de 1982 (...). Isto marca uma mudança importante da política previdenciária em relação a esta modalidade. E, já em 1984, os gastos com este tipo de convênio tornam-se inexpressivos na Previdência Social, representando 1\% da despesa com prestadores de serviço (MPAS/ INAMPS 1986)" (Conill 1993:70).

13 Esse incentivo desenvolve-se ao longo da década de 90 (embora só tenhamos dados de anos anteriores). Segundo Medici (1992a), “(...) durante muito tempo (pelo menos até 1986), tais recursos eram abatidos dos rendimentos auferidos para efeitos de cálculo de imposto a pagar. Tais abatimentos eram no entanto, limitados a despesas médicas e odontológicas efetivamente prestadas. Não estavam incluídos os recursos gastos com planos de saúde (...) embora para os assalariados que descontavam para entidades de previdência fechada que tinham, em seus planos, cobertura de serviços de saúde, estava embutido um incentivo ao consumo, limitado aos tetos especificados na legislação de imposto de renda de cada ano. Em virtude da prática de utilizar dois preços 'com recibo' e 'sem recibo' e dado que era possível a quem tinha muito imposto a pagar encontrar um médico ou serviço que pudesse emitir recibos falsos por valores inferiores aos registrados nos serviços) (...) na declaração do Imposto de Renda da Pessoa Física (IRPF) de 1988 (ano base de 1987), poderiam ser abatidas todas as despesas com a saúde do titular e seus dependentes (...), exceto aquelas pelas quais o indivíduo tenha sido reembolsado ou coberto por seguro (...). No entanto, a parcela gasta com saúde não reembolsada pela empresa poderia ser abatida desde que devidamente comprovada. Já na de 1990 (ano base 1989), só poderiam ser deduzidas as parcelas das despesas com médicos que, em cada mês, superassem $5 \%$ da renda bruta auferida naquele mês. Isto limitou muito a possibilidade de abatimento com despesas de saúde no IRPF. No entanto, poderiam ser abatidas as despesas gastas com 'seguro saúde' e 'medicina de grupo', que excedessem esse limite. Para 1991 (ano base de 1990) está previsto o retorno da restituição dos gastos em saúde no IRPF" (op.cit. 1992a:100-103).

14 Acreditamos que essa dedicação de maior tempo de trabalho por unidade de produção tem um duplo caráter: ela não se refere apenas a um possível aumento do tempo médio total do atendimento médico em si por unidade de produção (consultas, exames, internação, reabilitação etc.). Aquela "dedicação..." se verificaria também para si , digo, no aumento da quantidade de medicalização ao longo do tempo de vida dos homens e mulheres. Essa operação analítica, portanto, adicionaria uma dimensão temporal à observação da produção e da produtividade dos serviços de saúde, em suma, do trabalho médico por unidade de produção. Desse modo, na medida em que a intervenção médica, no bojo da expansão do conhecimento médico, tomaria mais tempo do cotidiano das pessoas num quadro de elevação da expectativa de vida, à primeira vista, seria uma boa pista tentar demonstrar o teorema dos custos crescentes, baseando-se naquela hipótese, qual seja, da baixa produtividade do trabalho dos serviços médicos. Em decorrência disso, restaria ainda o difícil desafio teórico-prático de mensurar de forma convincente a produtividade de tais serviços.

15 Em outros termos, a incorporação de tecnologia nos serviços de saúde aumenta seus custos fixos e pressiona ainda mais seus preços na medida em que o ingresso de progresso técnico não necessariamente representa um aumento da produtividade do trabalho em si.

16 Estamos admitindo aqui inclusive as inovações incrementais. Ver Schumpeter, J. (1943). "Capitalism, Socialism and Democracy". Londres: Allen \& Unwin. 
17 Algumas empresas médicas agora oferecem planos internacionais, diferenciando-se no processo de competição, reduzindo custos e mantendo a qualidade e, portanto, ganhando mercado.

18 À guisa de ilustração, cabe mencionar o documento do "Fórum de Líderes Empresariais 97 da Gazeta Mercantil" — Saúde: uma Emergência Nacional — que propõe rigorosamente que o Estado amplie a renúncia de arrecadação fiscal, os incentivos governamentais, com vistas à expansão do mercado dos planos de saúde. Tal ampliação sustenta-se sob o seguinte argumento: que as coberturas contratadas aos planos privados substituem as oferecidas pelo setor público, querendo fazer crer que o ressarcimento do SUS tenha sido e seja pura fantasia das tecnoburocracias e das forças sociais envolvidas no processo de discussão da implantação do projeto de regulamentação.

19 De forma bastante superficial, mark-up designa o que se cobra a mais do custo de produção. É desse mark-up que se identifica o lucro do agente econômico (Singer 1983). Nesse caso, as empresas de autogestão, que produzem um excedente econômico (cuja função social é distinta do lucro) devem ser tratadas de maneira diferenciada na análise de mercado.

20 O conceito de fundo público “(...) não é, portanto, a expressão apenas de recursos estatais destinados a sustentar ou financiar a acumulação de capital; ele é um mix que se forma dialeticamente e representa na mesma unidade, contém na mesma unidade, no mesmo movimento a razão do Estado, que é sócio-política, ou pública, se quisermos, e a razão dos capitais, que é privada" (Oliveira 1993:139).

21 Por hora, o conceito de regulação é apropriado com base na seguinte noção: “(...) regulação como intervenção ativa e consciente do Estado (...) com relação ao setorial, a multiplicação das regulamentações" (Boyer 1990:46).

22 O projeto de lei 9.656 de junho de 98 aprovado pelo Senado e sancionado pelo poder executivo será alterado sucessivamente mediante a edição de Medidas Provisórias. A partir daí, os planos de saúde terão 15 meses para adequar os seus contratos às novas normas.

23 Ver Luz (1991); Bahia (1991); Reis (1997); e Almeida (1997).

\section{Referências bibliográficas}

Andreazzi, M.F.S. (1991), O Seguro Saúde Privado no Brasil. Tese de mestrado. Rio de Janeiro: ENSP, FIOCRUZ.

BAHIA, L. (1992), Oferta e Produção de Serviços no Brasil na Década de 80: Um Estudo Exploratório. Tese de mestrado. Rio de Janeiro: ENSP, FIOCRUZ. . (1997), Características de Oferta e Cobertura dos Planos e Seguros no Brasil. Mimeo.

Banco Mundial. (1993), Relatório sobre o desenvolvimento mundial 1993. Investindo em saúde - Resumo. Washington, D.C.: Banco Mundial.

BAYER, G.F. \& Leis, H. (1986), "Saúde enquanto questão politicamente intermediada". Serviço Social \& Sociedade, 22, pp. 103-125.

Boyer, R. (1990), A Teoria da Regulação. São Paulo: Nobel.

Braga, J.C. \& Goés de Paula, S. (1986), Saúde e Previdência - Estudos de Política Social. São Paulo: Hucitec. 
Braverman, H. (1981), Trabalho e Capital Monopolista - A Degradação do Trabalho no Século XX. Rio de Janeiro: Zahar.

Conill, E.M. (1993), Modelo assistencial brasileiro: sistema único ou múltiplo de saúde? Considerações sobre a emergência e a evolução do seguro saúde privado no Brasil. Trabalho apresentado como requisito do concurso para professor adjunto no Dep. Saúde Pública/UFSC. Rio de Janeiro: Mimeo.

Cordeiro, H.A. (1984), As Empresas Médicas: as Transformações Capitalistas da Prática Médica. Rio de Janeiro: Graal. (1985), A indústria da Saúde no Brasil. Rio de Janeiro: Graal.

ERBER, F. (1980), “Tendência da economia mundial e suas implicações para a política tecnológica”. Série Políticas de Saúde (MS/FIOCRUZ), 2, pp. 27-43.

Favaret Filho, P. \& Oliveira, P.J. (1989), “A Universalização excludente”. Texto para Discussão (IEI/UFRJ), 216.

Fiori, J.L. (1994), "Debates sobre o ponto de crítico / consenso de Washington versus Apartheid”. Estudos em Saúde Coletiva (IMS/UERJ), 90.

Guimarães, E.A. (1982), Acumulação e o Crescimento da Firma - Um Estudo de Organização Industrial. Rio de Janeiro: Zahar.

LuZ, M.T. (1991), "Notas sobre as políticas de saúde no Brasil de "transição democrática" — anos 80”. PHYSIS/Revista de Saúde Coletiva, v. 1, 1, pp. 77-96.

M arques, M. B. (1991), Ciência, Tecnologia, Saúde e Desenvolvimento Sustentado. Rio de Janeiro: FIOCRUZ.

M ARX, K. (1985), O Capital: Crítica da Economia Política. São Paulo: Nova Cultural.

M aynard, A. (1996), "Reformas de sistemas de saúde: o papel de economia da saúde em informar escolhas difíceis". Anais do Seminário Internacional "Tópicos Conceituais e Metodológicos em Economia da Saúde” (org. M. Alicia Ugá), ABrES/FIOCRUZ, pp.11-26.

Medici, A.C. (1990a), “O setor privado prestador de serviços de saúde no Brasil: a dimensão, estrutura e funcionamento”. Relatórios Técnicos (ENCE/IBGE), 2.

(1990b), Financiamento e contenção de custos nas políticas de saúde - Tendências atuais e perspectivas futuras. Trabalho apresentado no Internacional Seminar on Health Policies. São Paulo: Mimeo.

(1991), “A medicina de grupo no Brasil". Série Desenvolvimento das Políticas de Saúde (OPAS), 1.

. (1992a), "Incentivos governamentais ao setor saúde no Brasil". Revista de Administração Pública, 2, pp. 79-115.

. (1992b), "Os serviços de assistência médica das empresas: evolução e tendências recentes”. Texto para Discussão (IESP/FUNDAP), 7.

Mendes, E.V. (1994), “As políticas de saúde no Brasil nos anos 80: a conformação da reforma sanitária e a construção da hegemonia do projeto neoliberal". Distrito sanitário - O Processo Social de Mudança das Práticas Sanitárias do SUS (E.Vilaça Mendes org.), pp.19-92, São Paulo/Rio de Janeiro: ABRASCO/HUCITEC.

Noronha, J.C. \& Levcovitz, E. (1994), "AIS - SUDS — SUS: os caminhos do direito à saúde”. Saúde e Sociedade no Brasil: anos 80 (orgs. Reinaldo Guimarães \& Ricardo Tavares). Rio de Janeiro: Relume Dumará.

Nunes, A. (1996), Imperfeições no Mercado de Saúde. A Saúde no Brasil. Tese de mestrado: Distrito Federal: Departamento de Economia/UNB.

Oliveira, F. (1988), "O Surgimento do antivalor. Capital, força de trabalho e fundo público". Novos Estudos CEBRAP, 22 pp. 8-28.

(1993), “A economia política da social-democracia". Revista USP, São Paulo, n. 17, pp. 136-143. 
Possas, M.L. (1985), Estruturas de Mercado em Oligopólio. São Paulo: HUCITEC.

Reis, C.O.O. (1995), O Setor Privado de Saúde no Brasil: Limites da Autonomia. Tese de mestrado. Rio de Janeiro: IMS, UERJ.

. (1997), "O setor privado "autônomo": um caso de política". Seminário: a Regulamentação dos Planos e Seguros Privados no Brasil (coord. Ana L. Viana \& C. Octávio Reis). Estudos em Saúde Coletiva (IMS/UERJ), 152, pp. 5-18.

Schumpeter, J.A. (1943), Capitalism, Socialism and Democracy. Londres: Allen \& Unwin. . (1982), Teoria do Desenvolvimento Econômico: uma investigação sobre Lucros, Capital, Crédito, Juro e o Ciclo Econômico. São Paulo: Abril Cultural. Singer, P. (1983), Aprender Economia. São Paulo: Brasiliense.

Suma Econômica. (1992), Medicina supletiva: a iniciativa privada cooperando com o Estado. São Paulo, n. 158, pp.41-42.

Ugá, M.A.D. (1997), Propostas de Reforma do Setor Saúde nos Marcos do Ajuste Macroeconômico. Tese de doutoramento. Rio de Janeiro: IMS, UERJ.

Viacava, F. \& Bahia, L. (1996), "Assistência Médico-Sanitária. Os serviços de saúde segundo o IBGE". Revista DADOS/RADIS, nov., n. 20, pp. 3-30.

Vianna, C. (1987), "Modelo de Funcionamento do Setor Privado dos Serviço Médicos do País". Cadernos do Instituto de Medicina Social (IMS/UERJ), 3, pp. 31-46. . et alli (1987), "O INAMPS e o Setor Prestador de Serviços Médicos". Diagnóstico de Alguns Obstáculos à uma ação Planejada do INAMPS (J.L.Fiori org.), Relatório final (IEI/INAMPS/FINEP).

Vogt, W. et alli (1980), Estado e Capitalismo. Rio de Janeiro: Tempo Brasileiro.

Werneck Vianna, M.L.T. (1989), "Política social e transição democrática: o caso do INAMPS”. Texto para discussão (IEI/UFRJ), 226.

. (1995), Articulação de Interesses, Estratégias de Bem-Estar e Políticas

Públicas: A Americanização (Perversa) da Seguridade Social no Brasil. Tese de doutoramento. Rio de Janeiro: Iuperj. 


\section{O Estado e os planos de saúde no Brasil Carlos Octávio Ocké Reis}

A partir da década de 60, o Estado viabilizou a expansão dos planos de saúde por meio de mediações com os gastos públicos da assistência médica previdenciária. Nas décadas seguintes esse mercado cresceu de forma autônoma.

Apontamos aqui como essa dinâmica autônoma residira apenas em parte na eficiência econômica das empresas médicas: na verdade, os planos mantiveram relações financeiras estruturais com o Estado via renúncia de arrecadação fiscal.

Assistimos agora à ascensão dos planos no sistema nacional de saúde. Esse mercado apresenta-se como uma alternativa na configuração do novo modelo assistencial, embora com alto grau de incerteza do ponto de vista da eqüidade.

Esse quadro multiplica os desafios da relação entre o Estado e os planos de saúde sobretudo no tocante à regulamentação.

\section{El Estado y los planes de salud en Brasil Carlos Octávio Ocké Reis}

A partir de los años 60, el Estado hizo posible la extensión de los planes de salud por medio de mediaciones con los gastos publicos del sistema médico en el seguro social. En las décadas siguientes ese mercado creció en forma autónoma.

Señalamos aquí que esta dinámica autónoma consistia solamente en parte en la eficiencia económica de las compañías médicas: en verdad, los planes hábian mantenido relaciones financieras estructurales con el Estado vía renúncias recaudación.

Ahora atendemos a la ascensión de los planes en el sistema nacional de la salud. Ese mercado se presenta como alternativa en el nuevo modelo assistencial, a pesar del alto grado de incertidumbre del punto de vista de la equidad.

Ese cuadro multiplica los desafíos de la relación entre el Estado y los planes de salud, en especial en lo que refiere a la regulación.

\section{The State and the healthcare plans in Brazil \\ Carlos Octávio Ocké Reis}

Starting in the 1960s, the State made the expansion of the health plans possible by means of public social security. In the following decades this market grew of autonomously.

We showed here that these autonomous dynamics consisted only in part of the economic efficiency of the medical companies themselves: actually, the plans kept structural financial relations with the State tax relief.

We are currently seeing an ascension of the plans in the national health system. This market is presented as an alternative in the shaping of the new assistential model, despite being highly uncertain from the point of view of equity.

This framework multiplies the challenges regarding the State/health plan relationship, especially on regulation issues.
Revista do

Serviço

Público

Ano 51

Número 1

Jan-Mar 2000

Economista e pesquisador da Diretoria de

Estudos Sociais

do Instituto

de Pesquisa

Econômica

Aplicada /IPEA.

Doutorando da

Escola de

Pós-graduação

em Saúde

Coletiva,

Instituto de

Medicina Social/

IMS/UERJ,

Rio de Janeiro 